\title{
Contrapsicología. Roberto Rodríguez (ed.). Madrid: Dado ediciones, 2016.
}

\author{
Concepción Fernández Villanueva \\ Universidad Complutense de Madrid \\ cfvillanueva@cps.ucm.es
}

Nos encontramos con una interesante y necesaria reflexión crítica sobre las bases ideológicas de la psicología y las consecuencias políticas de su aplicación. El libro desarrolla una perspectiva histórica que incluye desde los orígenes de la ciencia psicológica hasta su diversificación en múltiples contextos y formas en la actualidad. Las ideas que aporta son sustantivas para enmarcar y evaluar el quehacer de las Ilamadas prácticas psi y para reformular las opiniones y actitudes hacia un saber que nos acompaña a lo largo de cada vez mayor número de experiencias vitales.

Una primera cuestión que desvela un importante problema actual es la distinción entre la psicología científica y las prácticas vulgarizadas y mercantilizadas que proliferan hoy y que son vendidas como psicología alcanzando ámbitos de la cultura cada vez más amplios. Personas sin formación seria en psicología, que se llaman a sí mismos coach 0 especialistas en técnicas de dudosa fundamentación científica, ofrecen ayuda en distintos procesos, como problemas de trabajo, estados de ánimo o problemas de duelo o de pareja. Nos encontramos con una especie de mercadillo emocional que vende salud y bienestar con el consiguiente peligro para los usuarios que, como en el caso de técnicas médicas fraudulentas, pueden contribuir no solo a no mejorar sino a empeorar la salud psíquica de los usuarios. Las técnicas psicológicas han colonizado la cotidianeidad pero, así como a la psicología científica le costó un gran esfuerzo legitimarse y separarse de otras ciencias como la filosofía y la medicina, éstas técnicas, aun careciendo de formación y legitimidad similares a los que fueron exi-

gidos a la psicología para su ejercicio profesional, se han convertido en instrumentos de control social, en dispositivos de poder en el sentido foucaultiano. Como se explica en diversos artículos del libro, están sirviendo para hacer recaer sobre los individuos los costes del malestar que generan las demandas sociales y económicas del sistema de producción y organización social en que vivimos.

Las dimensiones ideológico-políticas de la misma psicología científica parecen hoy día difíciles de negar. Paralelamente al desarrollo de una amplia variedad de investigaciones y recursos de diagnóstico y de técnicas terapéuticas muy valiosas, ha surgido una fuerte tradición de pensamiento crítico que comienza revisando los orígenes de esta ciencia y sus funciones en los contextos sociales en que surgieron. Este texto es una colección de textos críticos que recopila las mejores aportaciones de sus autores.

Ya en el primer capítulo titulado La psicología como ciencia social, Nicholas Rose, uno de los autores más reconocidos en el debate de esta cuestión, señala que, frente a la opinión más o menos popular de que la psicología es una ciencia que trata sobre la mente individual, en la realidad fue una tecnología para que el individuo fuese operativo en el sistema social norteamericano. Mas que comprender el objetivo era controlar (transformar, modelar y o reformar a los sujetos) y por ello desde sus comienzos encontró un lugar en las técnicas del gobierno. Nació en el seno de proyectos políticos para administrar los sujetos. Y sus primeras aportaciones sobre el proceso de liderazgo, la opinión pública, el prejuicio, la relación entre razas, la selección de personal para el 
trabajo, la inadaptación de los sujetos, la dirección de colectivos cumplieron objetivos sociopolíticos. La politización de sus objetivos resultados se muestra de modo contundente desde entonces hasta la proliferación actual de los llamados prácticas "Psi".

Oscar Daza muestra como los test constituyeron un mecanismo muy útil para permitir materializar la llamada mente y hacerla calculable y administrable. La psicología diferencial promocionó el etiquetado de los rasgos individuales que se utilizó para justificar las desigualdades, para seleccionar y para excluir. La ideología de la eugenesia estuvo sostenida por algunos psicólogos como Galton, que pretendían seleccionar y promover la reproducción selectiva de los individuos más inteligentes, Pero no menos peligroso e igualmente político era la justificación de la educación excluyente o selectiva de los miembros de diversos orígenes étnicos 0 de distinto sexo.

Un rasgo característico del quehacer psicológico actual es la sobrevaloración de la idea de un yo separado, autónomo y controlado (o autocontrolado). Álvarez Uría indaga en los orígenes de la psicología del yo, de su sobrevaloración y sus relaciones con las producciones culturales y artísticas de los siglos xix y xx tal como se manifiestan en la literatura, la pintura y con la ideología del industrialismo. Asimismo resalta el importante papel de Freud y el psicoanálisis en la formación de una cultura psicológica que a través de sus conceptos tan conocidos hoy como ego, superyó, inconsciente, resistencia 0 represión, permitió reflexionar sobre la estructura psíquica de los individuos y sus aspectos desconocidos o reprimidos.

La reflexión epistemológica comienza con un interesante debate de lan Parker sobre los diagnósticos psicológicos y sus tratamientos. La categoría locura ha resultado funcional para el capitalismo moderno y cada uno de sus modelos ha estado legitimado por determinadas formas de poder que compiten entre sí defendiendo unas maneras de actuar de los profesionales y marginando otras. Los métodos de diagnóstico evidencian sus debilidades e incongruencias y la carga de criterios extra clínicos 0 de carácter social y político de las clasificaciones dominantes en la actualidad, entre ellas el Manual Diagnóstico y Estadístico de los Trastornos
Mentales (DSM). En consecuencia, se plantea la necesidad de repensar y reformular la locura y las prácticas clínicas sobre los sujetos diagnosticados de algún tipo de psicopatología. Todo ello sin olvidar las condiciones sociales que influyen en el desencadenamiento de los procesos psicopatológicos y las dimensiones sociales, éticas y de justicia social que deben estar presente en el ejercicio de las intervenciones. En el mismo sentido Ana Elúa muestra la heterogeneidad y dispersión de los diagnósticos de la patología mental, sus contradicciones y los criterios de carácter político y económico que están detrás de ellos. El análisis detallado del DSM muestra sus deficiencias en la administración a pacientes que han producido tanto falsos positivos (personas diagnosticadas de patologías que no tenían) como falsos negativos (personas que sufren los síndromes pero no son detectados por el test) y muestra los criterios extra clínicos que se han introducido tanto en su primitiva creación como en sus formulaciones posteriores. Un indicio muy evidente de la función política y social de este instrumento de diagnóstico se muestra en su insistencia en la idea de normalidad 0 anormalidad.

El repaso por el ámbito institucional muestra con mayor claridad aún el encaje histórico de las practicas psicológicas en el sistema jurídico penal, en los métodos de reeducación infantil y en la organización del trabajo. En todos estos contextos la psicología ha ejercido y puede ejercer una forma de violencia física o simbólica sobre los individuos con importantes efectos en su bienestar. Mario Domínguez muestra las diversas formas mediante las cuales el sistema penal ha promovido la insistencia en el control, la desviación, el sistema carcelario y la judicialización de los síntomas patológicos y de desajuste social de los menores. Julio Rubio muestra la violencia ejercida contra niños y niñas institucionalizados con la complicidad de las autoridades y, no pocas veces, con la ayuda de los profesionales de la psicología y la pedagogía.

Particularmente interesante y novedosa resulta la dimensión política de la psicología referida al ámbito del trabajo, que se trata en la reflexión de Eduardo Crespo y Amparo Serrano. La insistencia de la psicología del trabajo en las actitudes, las 
habilidades sociales, las motivaciones y la regulación emocional como condición para ejercer de forma adecuada un puesto de trabajo, reconfigura la relación de los sujetos con sus tareas laborales y la misma definición de trabajo. Los efectos políticos de esta transformación, son dobles. Por un lado, producen el cada vez mayor auto-disciplinamiento moral del trabajador, que se hace responsable de su salud y bienestar psicosocial a través del consumo de técnicas psicológicas muchas de ellas de dudosa importancia y efectividad terapéutica. Por otro lado, despolitiza el malestar de los trabajadores, desviando la atención de lo fundamental, los cambios necesarios en el sistema de trabajo. La desprotección sociolaboral (en sus manifestaciones de precarización, inseguridad, coerción, inestabilidad, explotación, etc.), queda invisibilizada y se subraya la culpabilización de los individuos por sus condiciones de vida y sus malestares, incluso por la pérdida de sus puestos de trabajo. Se trata de una forma de violencia simbólica impuesta a los trabajadores que queda oculta bajo la ideología de la autoeficacia, la flexibilidad del mercado de trabajo y la supuesta capacidad de decisión y libertad de los individuos.

El aumento de la medicalización es parte de este proceso de transformación de malestares sociales en síntomas que pueden ser resueltos desde el individuo a través de la ingestión de medicamentos. Guillermo Rendueles muestra una gran variedad de ejemplos cómo se han multiplicado los síndromes psicológicos susceptibles de ser medicados en línea con la multiplicación de los gestores y mecenas y mercaderes mentirosos de la oferta farmacéutica. Así se explican el encarnizamiento terapéutico y las medicaciones innecesarias, los diagnósticos inadecuados, culpabilizadores y tóxicos, los abusos de la psiquiatría. Las soluciones farmacológicas se aplican a cualquier distimia o problema 0 síntoma insuficientemente diagnosticado. La prescripción de fármacos no es nada rigurosa ni exigente en cuanto a la precisión de las patologías. Sus efectos son crear patologías nuevas, aunque no hayan sido suficientemente comprobadas y estabilizar y fortalecer las que ya han sido probadas, en la medida en que de ello depende la prosperidad económica de las industrias farmacéuticas.
El olvido de la categoría género en los instrumentos de diagnóstico y tratamiento de la psicopatología se nos muestran como otra forma de opresión y violencia. La interpretación inadecuada y androcéntrica de los síntomas psicológicos de las mujeres es otra forma de despolitizar los efectos de la dominación y hace recaer sobre los individuos, las mujeres, la tarea de defenderse y liberarse de ellos a su costa. Teresa Cabruja llega a afirmar que las ciencias psi ejercen violencia machista. La ginecología 0 la psiquiatría cuando se refieren a cuerpo femenino se desplazan desde la anatomía y fisiología genital a lo social y lo identitario, convirtiendo el cuerpo de la mujer en un constante efecto psicológico desproporcionado e inadecuado. El progresivo individualismo que descontextualiza los síntomas de sus dimensiones sociales junto con los dispositivos patriarcales ciegos a los efectos de la dominación, traducen las diferencias de género en un inadecuado recuento de cantidad de malestares entre hombres y mujeres. Es urgente de construcción de la psicopatología desde una perspectiva de género y reconocer y explicar las experiencias laborales de estrés y enfermedad que se tiene como mujeres y como feministas.

En el ámbito cultural, la psicología se ha vulgarizado dando lugar a una extensa literatura de autoayuda y autoconocimiento que. Lejos de ser fácil, útil y light como aparenta, impone una gestión personal de las subjetividades a la vez que una desimplicación de lo político. Se atiende casi exclusivamente a rasgos superficiales como la autoestima la autovaloración, la creatividad, tratándolos como factores que contribuyen a la liberación de los sujetos, mientras se descuidan, los necesarios elementos sociales que están detrás y explican estas expresiones subjetivas. La comunicación de los resultados de la ciencia psicológica a los grandes públicos se realiza en muchas ocasiones de forma sesgada e interesada. El texto de Silvia García Dauder y Patricia Amigot muestra como la psicología del género se explica en los medios de una forma tradicional y patriarcal. El análisis de discurso de los programas El cerebro masculino, El cerebro femenino y El cerebro tiene sexo, capítulos de la popular serie de programas redes para la ciencia, dirigida por Eduardo Punset, desvela las estrategias de imagen y representación de la información 
que tienen a restablecer los roles tradicionales de género como normales y diferentemente valorados. Con ello se refuerzan los ancestrales estereotipos de género. Estrategias de personificación de la madre naturaleza cómo "los óvulos se implican en el cuidado", "Ios espermatozoides compiten por una pareja" establecen un paralelismo inadecuado entre los estereotipos culturales del comportamiento masculino y femenino y el carácter de órganos biológicos como los óvulos y los espermatozoides. La trasposición de la explicación del funcionamiento de pequeños mecanismos del cerebro o las hormonas a la explicación de conductas muy complejas de hombres y mujeres, se hace de forma inadecuada y estereotipada. Se utiliza, además, un lenguaje sexista y androcéntrico que confunde lo universal y lo masculino. Desde un dualismo conceptual varón-hembra trasnochado, pero que resurge en nuevas metáforas, el varón aparece del lado de lo social, la cultura y lo humano universal, mientras que la mujer se cosifica del lado de lo biológico lo natural o lo animal. La selección de los materiales que presentan estos programas, los libros que reconocen y citan están igualmente sesgados para producir unas interpretaciones de la psicología del género en línea con los viejos estereotipos. Las autoras muestran con una claridad y contundencia de pruebas difícil de refutar, como se confunde la descripción de rasgos con la evaluación sexista de los mismos y como se intenta construir y reavivar la idea de inmutabilidad natural que siempre ha sido aliada de las actitudes conservadoras.

En suma, las, reflexiones, que contiene este texto son interesantes no solo para los que actúan en la práctica psicológica sino también para todos aquellos que intervienen desde la política o la planificación social en las vidas y las condiciones de trabajo de los colectivos y grupos humanos. Una constante une todos ellos: es necesario volver a considerar los efectos de las condiciones sociales en los individuos en vez de cargar sobre los individuos el coste de liberarse del malestar que dichas condiciones les producen. La psicología no debe ser cómplice de la despolitización social en todos los contextos ni de que el control externo se convierta cada vez más en control interno. No debe ser cómplice de ninguna violencia real 0 simbólica contra los individuos. 